\title{
Supporting Cells Eliminate Dying Sensory Hair Cells to Maintain Epithelial Integrity in the Avian Inner Ear
}

\author{
Jonathan E. Bird, ${ }^{1,2}$ Nicolas Daudet, ${ }^{1}$ Mark E. Warchol, ${ }^{4}$ and Jonathan E. Gale ${ }^{1,2,3}$ \\ ${ }^{1}$ UCL Ear Institute, University College London, London WC1X 8EE, United Kingdom, Departments of ${ }^{2}$ Physiology and ${ }^{3}$ Cell and Developmental Biology, \\ University College London, London WC1E 6BT, United Kingdom, and ${ }^{4}$ Department of Otolaryngology, Washington University School of Medicine, St. \\ Louis, Missouri 63110
}

Epithelial homeostasis is essential for sensory transduction in the auditory and vestibular organs of the inner ear, but how it is maintained during trauma is poorly understood. To examine potential repair mechanisms, we expressed $\beta$-actin-enhanced green fluorescent protein (EGFP) in the chick inner ear and used live-cell imaging to study how sensory epithelia responded during aminoglycoside-induced hair cell trauma. We found that glial-like supporting cells used two independent mechanisms to rapidly eliminate dying hair cells. Supporting cells assembled an actin cable at the luminal surface that extended around the pericuticular junction and constricted to excise the stereocilia bundle and cuticular plate from the hair cell soma. Hair bundle excision could occur within 3 min of actin-cable formation. After bundle excision, typically with a delay of up to 2-3 h, supporting cells engulfed and phagocytosed the remaining bundle-less hair cell. Dual-channel recordings with $\beta$-actin-EGFP and vital dyes revealed phagocytosis was concurrent with loss of hair cell integrity. We conclude that supporting cells repaired the epithelial barrier before hair cell plasmalemmal integrity was lost and that supporting cell activity was closely linked to hair cell death. Treatment with the Rho-kinase inhibitor Y-27632 did not prevent bundle excision but prolonged phagocytic engulfment and resulted in hair cell corpses accumulating within the epithelium. Our data show that supporting cells not only maintain epithelial integrity during trauma but suggest they may also be an integral part of the hair cell death process itself.

\section{Introduction}

Hair cells are the primary sensory receptors of the inner ear that detect sound and accelerations of the head (Hudspeth, 1997). Hair cells operate within a precisely defined extracellular environment that supports mechanoelectric transduction. Actinbased stereocilia extending from the surface of the hair cell are bathed in a luminal endolymph $\left(\sim 150 \mathrm{mM} \mathrm{K}^{+}\right)$, whereas an interstitial perilymph $\left(\sim 5 \mathrm{~mm} \mathrm{~K}^{+}\right)$surrounds the basolateral cell membranes. Homeostasis of endolymph and perilymph is maintained by multiple mechanisms that are critical for sensory transduction and hair cell survival (Wangemann, 2006). Nonsensory supporting cells further contribute to inner ear homeostasis by forming an epithelial barrier with hair cells to limit paracellular ion flux between endolymph and perilymph. The importance of the epithelial barrier is highlighted in animals with mutations in tight junction proteins CLDN9, CLDN14 and TRIC, where the ingress of endolymph results in hair cell degeneration (Wilcox et

Received June 14, 2010; revised July 19, 2010; accepted July 27, 2010.

This work was supported by a Medical Research Council Studentship (J.E.B.), Deafness Research UK Grants 421:UEl:JG (J.E.B., J.E.G.) and 433:EIP:DM (N.D.), National Institute on Deafness and Other Communication Disorders Grant R01DC006283 (M.E.W.), the Wolfson Foundation, and a Royal Society University Research Fellowship (J.E.G.). We thankJ. Corwin, F. Davison, and S. Moss for their gifts of anti-HCS1, anti-Av53, and cDNA encoding $\beta$-actin-EGFP, respectively. We also thank A. Forge, B. Baum, and G. Richardson for helpful discussions, and T. Friedman for critical reading of this manuscript.

Correspondence should be addressed to Jonathan E. Gale, UCL Ear Institute, 332 Gray's Inn Road, London WC1X 8EE, UK. E-mail: j.e.gale@ucl.ac.uk.

J. E. Bird's present address: Section on Human Genetics, National Institute on Deafness and Other Communication Disorders, National Institutes of Health, Rockville, MD 20850. E-mail: birdjo@nided.nih.gov.

DOI:10.1523/JNEUROSCI.3042-10.2010

Copyright $\odot 2010$ the authors $\quad$ 0270-6474/10/3012545-12\$15.00/0 al., 2001; Ben-Yosef et al., 2003; Riazuddin et al., 2006; Nakano et al., 2009).

Hair cell epithelia are susceptible to environmental traumas that can compromise barrier integrity and thus fluid homeostasis. Noise exposure can perforate the epithelium, providing a direct route for endolymph to infiltrate the interstitial spaces (Bohne and Rabbitt, 1983; Wang et al., 2002). Ototoxic compounds such as aminoglycoside antibiotics can also cause significant disruption by inducing apoptosis throughout the epithelium (Forge and Li, 2000; Pirvola et al., 2000; Matsui et al., 2003). As hair cells die, neighboring supporting cells expand and reform the apical junctions of the sensory epithelium (Hawkins, 1973; Bohne and Rabbitt, 1983; Forge, 1985 ), a process requiring actin polymerization (Raphael and Altschuler, 1991; Gale et al., 2002; Hordichok and Steyger, 2007). Ultrastructural studies suggest that as the epithelium repairs, supporting cell microfilaments can penetrate beneath the hair cell cuticular plate and separate the cell apex from its soma ( $\mathrm{Li}$ et al., 1995; Gale et al., 2002). It was proposed that supporting cells might use a multicellular actin cable to drive this process (Gale et al., 2002; Hordichok and Steyger, 2007). Actin cables harness the contraction of actomyosin filaments to power morphogenesis and epithelial repair in a range of systems (Martin and Lewis, 1992; Bement et al., 1993; Wood et al., 2002), and have also been observed in the mammalian utricle after large mechanical injuries (Meyers and Corwin, 2007). Furthermore, actin cables eject apoptotic cells from UV-irradiated Madin Darby canine kidney (MDCK) monolayers while continually maintaining barrier integrity (Rosenblatt et al., 2001; Slattum et al., 2009). Barrier integrity is also thought to be maintained during hair cell death 
(McDowell et al., 1989), but whether a similar actin-cable-based mechanism is responsible remains unknown.

In this report, we combined in ovo electroporation of a retroviral $\beta$-actin-enhanced green fluorescent protein (EGFP) plasmid with live imaging to explore the mechanisms of epithelial repair and hair cell removal. We show that supporting cells not only repair the epithelial barrier using an actin cable-based mechanism, but they subsequently go on to phagocytose the dying hair cell. These data provide direct evidence that supporting cells maintain epithelial homeostasis in the inner ear.

\section{Materials and Methods}

Reagents. Cell culture media, Alexa-conjugated secondary antibodies, TOTO-3 iodide (TOTO-3), and propidium iodide (PI) were obtained from Invitrogen. Glass-bottomed culture dishes were from Mattek. All other reagents were from Sigma. Monoclonal mouse hair cell soma-1 (HCS-1) antibody was a gift from J. Corwin (University of Virginia, Charlottesville, VA). Monoclonal mouse Av53 antibody was a gift from F. Davison (Institute of Animal Health, Pirbright, UK). Monoclonal mouse Racl antibody (catalog \#610651) was from BD Biosciences. Y-27632 (Tocris Bioscience) was reconstituted at a stock concentration of $30 \mathrm{~mm}(1000 \times)$ in sterile water.

Plasmids. The cDNA encoding an enhanced GFP human $\beta$-actin fusion protein was excised from a pcDNA3.1 vector (a gift from S. Moss, Institute of Ophthalmology, London, UK) and subcloned into the Cla12 adaptor plasmid to introduce ClaI sites flanking the ORF (Hughes et al., 1987). The $\beta$-actin-EGFP ORF was excised using ClaI restriction endonuclease and ligated into the ClaI site of the replication-competent ASLV (avian sarcoma-leukosis virus) long terminal repeat with a splice acceptor, Bryan polymerase, and B envelope $[\mathrm{RCASBP}(\mathrm{B})]$ construct to generate the RCASBP(B)- $\beta$-actin-EGFP plasmid (for review, see Morgan and Fekete, 1996). The orientation and integrity of the ORF was confirmed by sequencing. Plasmid DNA was prepared using an endotoxinfree purification kit (Qiagen).

Animals. Fertile White Leghorn (Gallus domesticus) chicken eggs were obtained from Henry Stewart and maintained in a humidified incubator at $37-38^{\circ} \mathrm{C}$. All animal care and experimental procedures were approved by a local University College London ethics committee and the UK Home Office.

Aminoglycoside administration in vivo. For in vivo experiments, fertile White Leghorn chicken eggs were obtained from Charles River SPAFAS. Eggs were incubated at $37-38^{\circ} \mathrm{C}$ in a humidified environment, and hatchling chicks were kept in heated brooders until required. Beginning at posthatch day 14 (P14), chicks received daily injections of streptomycin sulfate (in $0.9 \% \mathrm{NaCl}, 1200 \mathrm{mg} / \mathrm{kg}$, i.m.) for 5 consecutive days. Prior studies have shown that this treatment regimen results in the death of nearly all hair cells in the striolar region of the utricle (Warchol and Speck, 2007). Two days after the final injection (i.e., at P21), the animals were killed via $\mathrm{CO}_{2}$ asphyxiation. The utricles were quickly removed and fixed for 30 min in $4 \%$ paraformaldehyde. After thorough rinsing in PBS, specimens were processed for immunocytochemical labeling, as described below. All experimental procedures involving posthatch chicks were approved by the Washington University Animal Care and Use Committee in accordance with National Institutes of Health guidelines.

In ovo electroporation. In ovo electroporation of the otic cup was performed as described previously (Daudet and Lewis, 2005). Chicken embryos were staged according to the Hamburger and Hamilton (1992) classification. Concentrated plasmid DNA $(1 \mu \mathrm{g} / \mu \mathrm{l})$ was injected into the right developing otic cup (stage 14) and a pulse train immediately applied along the mediolateral axis of the embryo $(4 \times 30 \mathrm{~ms}, 10 \mathrm{~V}$; ECM 830, BTX). After electroporation, the egg was resealed using clear sticky tape and returned to the incubator. Electroporated embryos were killed between embryonic day 17 (E17) and E19.

Inner ear explant preparation. Wild-type chicks were killed on E21 and RCAS-infected embryos between E17 and E19. Skulls were bisected and transferred into sterile dissection media (Medium 199, Hank's salts, 25 mM HEPES) in a laminar flow cabinet. Utricles were removed from the temporal bone and transferred into fresh dissection media. The otolithic membrane was aspirated using a gentle fluid jet.

Explant culture and in vitro aminoglycoside treatment. Utricles were cultured as described previously, with minor modifications (Matsui et al., 2000). Briefly, explants were maintained free floating in 24-well culture plates containing $0.5 \mathrm{ml}$ media per well (Medium 199, Earle's salts, 25 mM HEPES, $2.5 \%$ heat-inactivated FBS) in a $37^{\circ} \mathrm{C}, 5 \% \mathrm{CO}_{2}$ environment. After an initial $24 \mathrm{~h}$ adaptation to culture, utricles were switched into culture media containing $1 \mathrm{~mm}$ streptomycin sulfate and, optionally, $30 \mu \mathrm{M}$ Y-27632 [(R)-(+)-trans- $N$-(4-pyridyl)-4-(1-aminoethyl)cyclohexanecarboxamide]. Explants were maintained in this media for 12,18 , or $24 \mathrm{~h}$ before fixation. A $48 \mathrm{~h}$ treatment group was established using $24 \mathrm{~h}$ of incubation with streptomycin followed by an additional $24 \mathrm{~h}$ in normal media. Sham-operated utricles incubated for the initial $24 \mathrm{~h}$ adaptation period plus an additional $24 \mathrm{~h}$ in normal media served as controls.

Immunocytochemistry. Samples were fixed in 4\% paraformaldehyde for $30 \mathrm{~min}$ and washed thoroughly with PBS. Samples were incubated in blocking solution (PBS, $0.2 \%$ Triton X-100, 10\% normal horse serum) for $1 \mathrm{~h}$ to permeabilize the tissue and reduce nonspecific antibody binding. Primary antibodies were diluted in blocking solution and incubated overnight at $4^{\circ} \mathrm{C}$. Subsequent detection was with a fluorescent Alexaconjugated anti-IgG. Samples were counterstained using Alexa-conjugated phalloidin and 4',6'-diamidino-2-phenylindole (DAPI), and mounted beneath a glass coverslip (\#0) in Fluoromount-F (Southern Biotech). Samples were visualized using an inverted Zeiss LSM 510 confocal microscope equipped with a $63 \times$ oil objective [1.4 numerical aperture (NA); Plan-Apochromat].

Live cell imaging. Acutely isolated explants were transferred to imaging chambers (\#0 coverglass; Mattek) and imaged in Medium 199 (Earle's salts, $2.5 \%$ FBS), optionally containing $1 \mathrm{~mm}$ streptomycin sulfate, 0.1 $\mu \mathrm{M}$ TOTO-3, or $1 \mu \mathrm{M}$ PI. A platinum wire threaded with fine nylon was used to weigh down the explant with the epithelial lumen facing toward the coverglass. Explants were imaged using a spinning disk confocal scanning unit (CSU-21; Yokogawa) attached to a Zeiss Axiovert 200 inverted microscope with a $63 \times$ oil objective (1.4 NA; Plan-Apochromat). An EM-CCD camera (iXon DV-887; Andor) in combination with a Z-drive (Piezosystem) was used to capture sequential volumes every 90-300 s using IQ software (Andor). The 488, 568, and $647 \mathrm{~nm}$ lines of a mixedgas Argon/Krypton laser were used to excite the sample (Melles Griot). For optimal cell survival and optical stability, the entire microscope was incubated at $37^{\circ} \mathrm{C}$, and a smaller stage mounted chamber maintained the sample in a $5 \% \mathrm{CO}_{2}$ atmosphere.

For imaging EGFP (488 nm excitation), a single-notch $488 \mathrm{~nm}$ dichroic mirror was used in conjunction with a $505 \mathrm{~nm}$ long-pass emission filter to ensure maximum transmission. For multiwavelength recordings, a 488/568/647 $\mathrm{nm}$ triple-band dichroic mirror was used with a bandpass $530 \mathrm{~nm}$, bandpass $580 \mathrm{~nm}$, or long-pass $650 \mathrm{~nm}$ emission filter.

Data analyses. Data and graphs were tabulated and prepared using Microsoft Excel and GraphPad Prism. All data are expressed as mean \pm SEM, and statistical significance was assessed using a two-tailed Student's $t$ test unless specified otherwise. Figures were prepared in Adobe Illustrator.

To assess hair cell density in fixed utricles, confocal z-series were loaded into OsiriX Open Source Imaging Software (OsiriX Foundation). Two mutually exclusive objects were quantified: hair cells and phagosomes. Hair cells were identified as having both (1) HCS-1 labeling restricted to the basolateral membrane of the cell and (2) a stereocilia bundle continuous with the cell soma. Phagosomes were identified as containing HCS-1 labeling but not being continuous with a stereocilia bundle. In addition, phagosomes were bounded by F-actin. For each utricle, two $200 \times 200 \mu \mathrm{m}$ extrastriolar regions were selected blindly and counted. These values were averaged to yield an overall density estimate (total sample area, $80000 \mu \mathrm{m}^{2}$ ). All estimates were made blind with respect to treatment group.

Multidimensional time-lapse data sets were viewed and processed using ImageJ and Matlab (MathWorks). Time-lapse images suffered from lateral drift, especially as the epithelium remodeled during hair cell death. To mitigate this, a Matlab script was written to identify lateral movements using fast Fourier transforms. Inverse affine transformations were 
then applied to reregister images to the initial reference frame. To quantify supporting cell activity during hair bundle excision, maximal z-projections were made that encompassed the apical junction complexes. Fluctuations in illumination intensity were corrected by ratioing each frame to the background. A circular region of interest (ROI) was positioned to encompass the hair cell and surrounding supporting cell junctions and the mean fluorescence intensity, $I(t)$, computed as a function of frame number $(t)$. A rise time, $T_{\text {rise, }}$, was defined as the period for $I(t)$ to transition between 10 and $100 \%$ of its peak value. After reaching its peak, $I(t)$ declined at a rate that was well approximated by a single exponential decay with a half-life, $T_{\text {half-life }}$. The lifetime was calculated as lifetime $=T_{\text {rise }}+T_{\text {half-life }}$. To avoid fluorescence artifacts when the highly fluorescent hair bundle was removed, our analysis was restricted to cellular mosaics in which hair cell expression of $\beta$-actin-EGFP was negligible or absent.

Supporting cell activity during phagocytosis was heterogeneous, and the average fluorescence intensity, $I(t)$, was not well described by the previous technique. Instead, activity was modeled as a spiking phenomenon. Maximal z-projections that excluded the apical junction complexes were made. Projections were median filtered to reduce high-frequency noise and the difference between sequential frames (regardless of sign) computed by subtracting $I(n)$ from $I(n-1)$ followed by a modulus function. Using this data set, a ROI was centered over the hair cell and surrounding supporting cells to calculate an average difference per frame. Events were defined where the average value exceeded a baseline average by three SDs. Event times were tabulated for each cell and the lifetime quoted as the 75 percentile $\left(Q_{3}\right)$ of this cumulative distribution. $\mathrm{Q}_{3}$ represents the time within which $75 \%$ of all suprathreshold events occurred and was chosen as an estimate that was insensitive to outlying data points and noise. To quantify the timing of phagocytosis relative to the loss of cell integrity, hair cell somas were selected blindly using the TOTO-3/PI signal and the fluorescence intensity was monitored on a frame-by-frame basis. Hair cells were assumed to have lost integrity when TOTO-3/PI fluorescence exceeded a background sample by three SDs. The $\beta$-actin-EGFP signal was then revealed and the frame interval to the onset of supporting cell engulfment calculated.

\section{Results}

Live-cell visualization of $\boldsymbol{\beta}$-actin-EGFP in the avian inner ear To investigate epithelial repair during hair cell trauma, we developed a model system to visualize actin dynamics in live explants of the inner ear. We took advantage of the RCAS system that allows simple transgenesis in the developing chick embryo (Morgan and Fekete, 1996). RCAS is a family of replication competent retroviral vectors, derived from the avian Rous sarcoma virus, in which the oncogenic $v$-src is replaced with an ORF of interest (Hughes et al., 1987). Proviral RCASBP(B) DNA containing the $\beta$-actin-EGFP coding sequence was generated and electroporated directly into the otic cup of stage 14 chick embryos. Within $24 \mathrm{~h}$ of electroporation, robust expression of $\beta$-actin-EGFP was observed throughout the otocyst (Fig. 1 $A, B$ ). Expression persisted until at least E19, the latest time point assayed in our experiments, suggesting that $\beta$-actinEGFP became stably integrated. We observed expression in all inner ear sensory organs, including the basilar papilla and the utricle. Within the utricular macula, expression was observed in both striolar and extrastriolar sensory hair cells, nonsensory supporting cells (Fig. 1C), and in stromal tissues (data not shown). The stochastic nature of viral infection and clonal expansion created mosaics of $\beta$-actin-EGFP expression that allowed the cytoskeleton of individual cells to be clearly discriminated. In utricular hair cells, $\beta$-actin-EGFP was highly concentrated in the stereocilia (Schneider et al., 2002; Rzadzinska et al., 2004), and to a lesser extent around the pericuticular necklace at the epithelial lumen (Fig. 1C). High-resolution laserscanning confocal microscopy of live hair bundles revealed that stereocilia retained their precise geometric organization, indicating that ectopic expression of $\beta$-actin-EGFP was not interfering with the formation of these intricate subcellular organelles (Fig. 1E,F). We
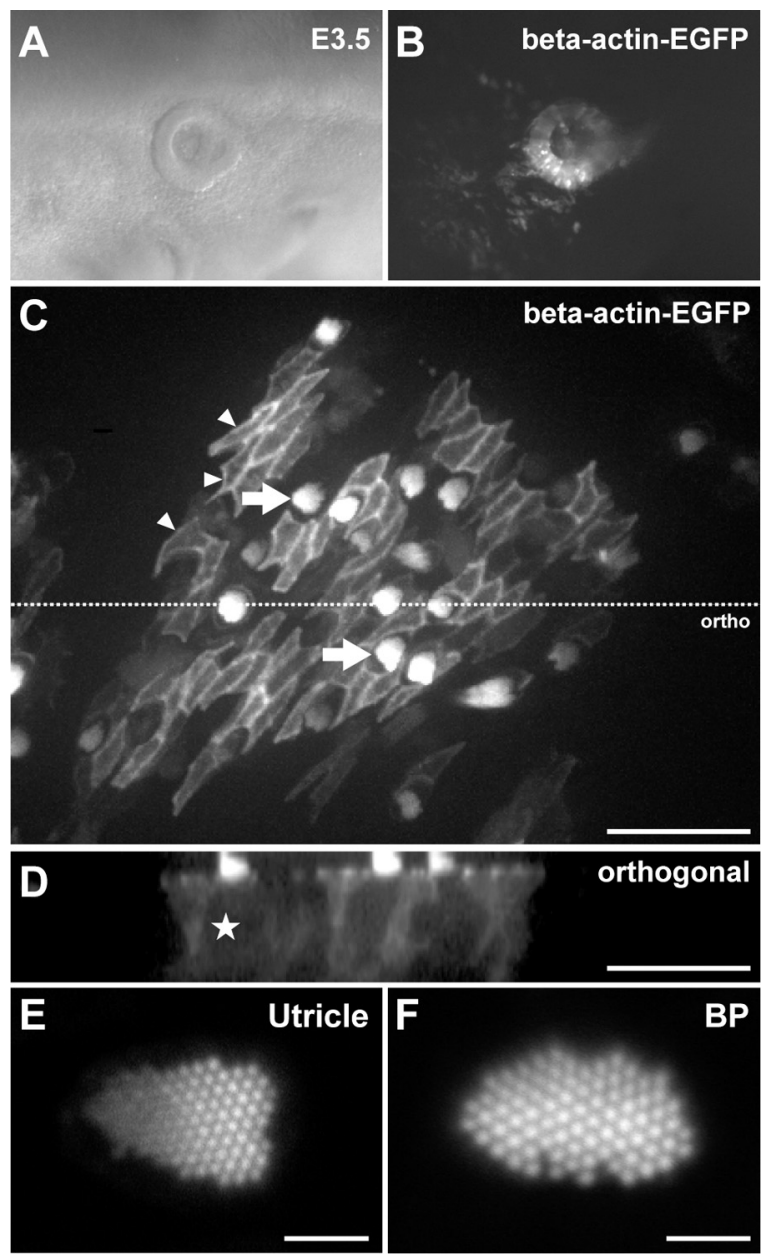

Figure 1. Live-cell imaging of $\beta$-actin-EGFP in the avian inner ear. RCASBP(B)- $\beta$-actinEGFP was transfected into an E2.5 otic cup by in ovo electroporation. $A, B$, Twenty-four hours later, $\beta$-actin-EGFP was expressed throughout the otic vesicle. $\boldsymbol{C}$, An example of $\beta$-actin-EGFP expression in a utricle isolated from a transgenic E18 embryo. The extrastriolar region was imaged live using a spinning-disk confocal microscope. The cellular mosaic of $\beta$-actin-EGFP expression allowed the cytoskeleton of hair cells and supporting cells to be discriminated. $\beta$-actin-EGFP was particularly concentrated in the apical junctions of supporting cells (small arrowheads) and hair cell stereocilia (arrows). $\boldsymbol{D}$, Orthogonal projection of $\boldsymbol{C}$. Hair cell somas (e.g., star) are identified by their low cytosolic $\beta$-actin-EGFP fluorescence compared to adjacent supporting cells. $\boldsymbol{E}, \boldsymbol{F}$, Expression of $\beta$-actin-EGFP did not affect development of actin-based structures at the subcellular level. Laser-scanning confocal imaging of live stereocilia bundles in the utricle $(\boldsymbol{E})$ and basilar papilla $(\boldsymbol{F})$ revealed a normal architecture. Scale bars: $\boldsymbol{C}, \boldsymbol{D}, 50 \mu \mathrm{m} ; \boldsymbol{E}$, $\boldsymbol{F}, 2 \mu \mathrm{m}$.

observed very low levels of $\beta$-actin-EGFP in the hair cell cytosol, consistent with gamma-actin being the predominant isoform present (Furness et al., 2005). In supporting cells, $\beta$-actin-EGFP was concentrated at the apical junction complexes, around the basolateral cortex, and diffusely throughout the cytosol (Fig. 1C,D). These results show that in ovo electroporation of RCASBP(B)- $\beta$-actinEGFP is an effective way to visualize the cytoskeleton in late stage chick embryos with minimal disruption to inner ear morphology.

\section{Supporting cells coordinate to rapidly excise the hair cell stereocilia and cuticular plate}

To induce hair cell death, utricles expressing $\beta$-actin-EGFP were treated with $1 \mathrm{~mm}$ streptomycin sulfate, an aminoglycoside antibiotic commonly used to treat Gram-negative bacterial infections. The selective toxicity of aminoglycoside antibiotics toward sensory hair cells is likely attributable to their direct uptake 

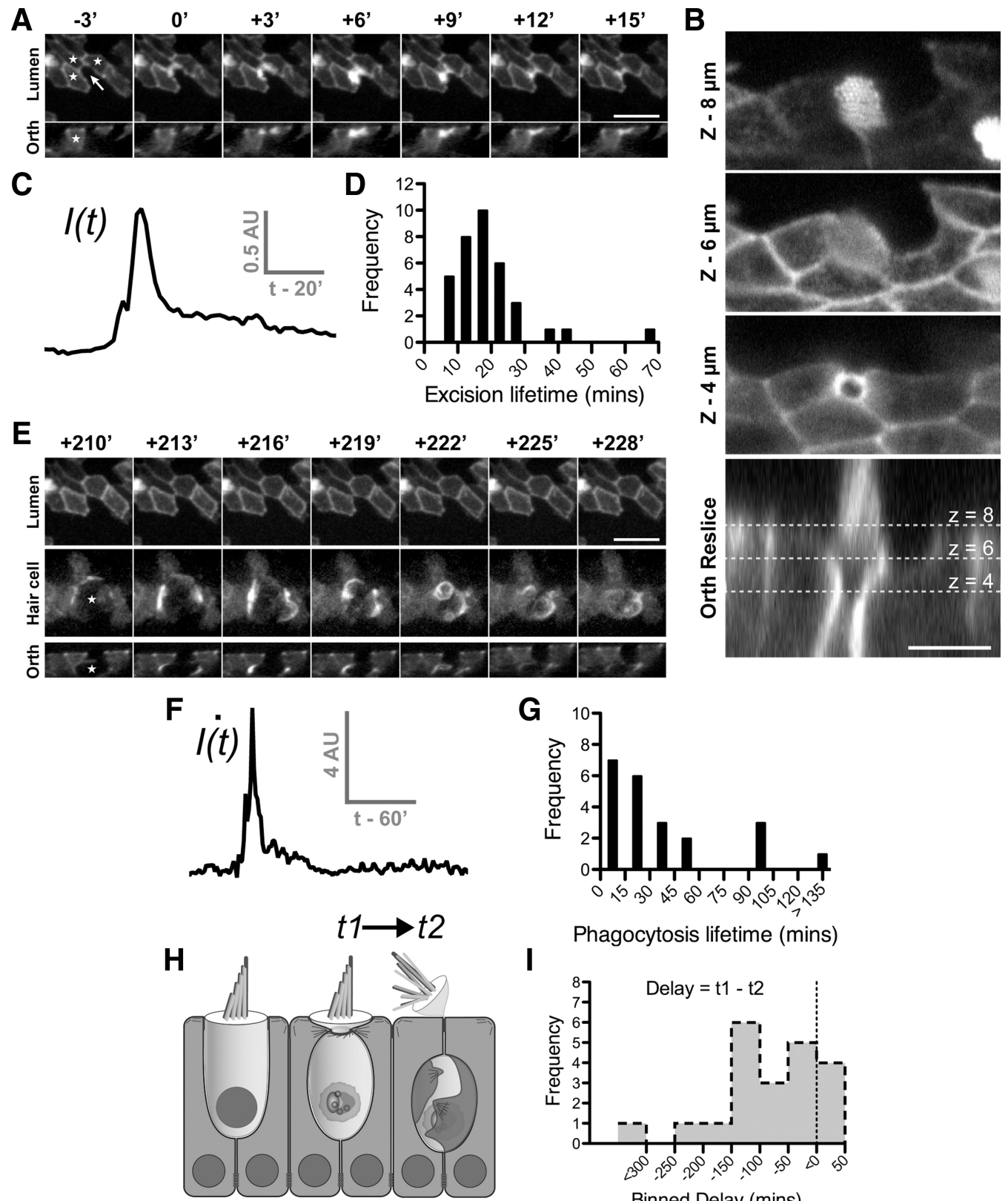

Phagocytosis lifetime (mins)

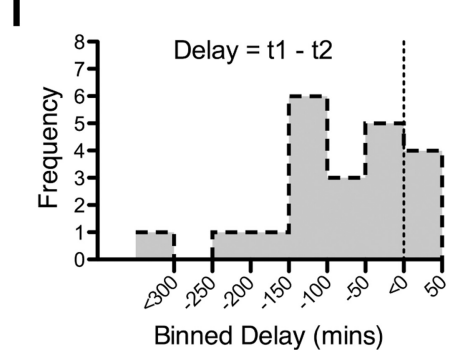

Figure 2. Supporting cells drive epithelial repair in the avian utricle using two distinct mechanisms. Transgenic utricles (E17-E19) expressing $\beta$-actin-EGFP were time-lapse imaged live in the presence of $1 \mathrm{~mm}$ streptomycin to induce hair cell death. $\boldsymbol{A}, \boldsymbol{E}, \mathrm{A}$ time-lapse sequence of hair cell removal and epithelial repair after at least $12 \mathrm{~h}$ of streptomycin treatment. Panels depict the exact same hair cell at different times during the repair process. In this mosaic, only supporting cells (stars) were expressing $\beta$-actin-EGFP. A nonexpressing hair cell was present in the center of the mosaic (arrow). A, Activity was initially restricted to the epithelial lumen where supporting cells formed an actin cable $\left(0^{\prime}\right)$ that invaded into the hair cell $\left(+3^{\prime}\right)$ and excised the stereocilia bundle $\left(+6^{\prime}\right)$. Junction complexes reformed after removal of the stereocilia bundle $\left(+15^{\prime}\right) \cdot \boldsymbol{B}$, Higher-resolution laser-scanning confocal image of a different hair cell shows how the actin cable constricts beneath the cuticular plate to eject the stereocilia bundle. C, Changes in fluorescence intensity of supporting cell $\beta$-actin-EGFP measured at the luminal surface during stereocilia excision. $\boldsymbol{D}$, Distribution of supporting cell activity during stereocilia excision ( $n=36$ events). $\boldsymbol{E}$, After stereocilia excision (shown in $\boldsymbol{A}$ ) supporting cells engulfed the remaining hair cell soma (star) within a phagosome highlighted by $\beta$-actin-EGFP.F, Supporting cell activity during phagocytosis was heterogeneous and was best modeled as a spiking phenomenon. Frame-by-frame differential fluorescence intensity was used to detect suprathreshold activity. The initial burst of activity represents formation of the phagosome, followed by an extended period where the cell is internalized. $\mathbf{G}$, Distribution of supporting cell activity during phagocytosis $(n=22$ events). $\boldsymbol{H}$, Schematic of the hair cell removal process. $\boldsymbol{I}$, Distribution of delay $(t 1-t 2)$ between onset of stereocilia excision $(t 1)$ and phagocytosis ( $t 2$ ). The majority of stereocilia excision events occurred in advance of hair cell phagocytosis. Scale bars: $\boldsymbol{A}, \boldsymbol{E}, 10 \mu \mathrm{m} ; \boldsymbol{B}, 5 \mu \mathrm{m}$. Times are expressed in minutes (').

through mechanotransduction channels (Gale et al., 2001; Marcotti et al., 2005). Utricles were time-lapse imaged on a spinning-disk confocal microscope in the continuous presence of streptomycin. Expression of $\beta$-actin-EGFP was most frequently observed in the extrastriolar zone, and thus we focused our attention on the type II hair cells that solely populate this area of the utricular macula.
Consistent with the reported time course of streptomycin toxicity in the utricular macular in vitro, at least $12 \mathrm{~h}$ elapsed before we started to see removal of hair cells from the epithelium (Matsui et al., 2000). Examination of the $\beta$-actin-EGFP time-lapse data sets revealed a complex series of cytoskeletal events that were coincident with epithelial repair and hair cell removal. These segregated into two distinct phases: the first presented at the lu- 
minal surface, whereas the second was observed deeper within the epithelium. Figure 2 shows a typical example of the epithelial repair process surrounding type II hair cells in the utricular macula. In this example, the fluorescent mosaic consisted of four supporting cells (three positive for $\beta$-actin-EGFP and the other negative) surrounding a negative hair cell (Fig. $2 A$ ). Although the hair cell was not visible using epifluorescence, its position within the epithelium was clearly demarcated by the neighboring supporting cells. The advantage conferred by this type of mosaic was that it allowed supporting cells' actin cytoskeleton to be visualized exclusively. We found that the first stage of the repair process was restricted to the luminal surface of the epithelium, where supporting cell $\beta$-actin-EGFP accumulated around the hair cell's pericuticular junction in a cable-like fashion (Fig. $2 A$ ). No signal could be detected at the junction between the hair cell and the nonexpressing supporting cell, indicating that each supporting cell initially contributed to its own discrete segment along the circumference of the actin cable. Supporting cell processes highlighted by $\beta$-actin-EGFP invaded into the hair cell's space over a period of $3 \mathrm{~min}$, where they proceeded to reform junctions at the epithelial surface (Fig. 2 A; supplemental Movie 1, available at www.jneurosci.org as supplemental material). We confirmed the fate of the hair cell's stereocilia bundle by imaging mosaics where the hair cell was expressing $\beta$-actin-EGFP in addition to the surrounding supporting cells (Fig. $2 B$; supplemental Movie 2, available at www.jneurosci.org as supplemental material). In these examples, the stereocilia bundle is clearly excised and ejected into the epithelial lumen, while the hair cell soma remains in the epithelium, consistent with SEM studies in the chicken utricle (Matsui et al., 2000). Orthogonal reconstructions of these data sets confirmed that the excision event was restricted to the epithelial lumen and also revealed that the hair bundle was likely excised beneath the cuticular plate (Fig. 2 B). After excision of the hair bundle, $\beta$-actin-EGFP fluorescence continued to fluctuate, indicative of an ongoing remodeling process at the epithelial junctions. Since we saw essentially the same response regardless of whether the hair cell was expressing $\beta$-actin-EGFP or not (Fig. $2 A$; supplemental Movie 2, available at www.jneurosci.org as supplemental material), we concluded that the actin cable originated from supporting cells.

To determine supporting cell cytoskeletal kinetics during stereocilia excision, we quantified the average $\beta$-actin-EGFP fluorescence in the pericuticular region as a function of time. To avoid out of focus contributions from the highly fluorescent hair bundle, our analysis was restricted to mosaics where hair cell expression of $\beta$-actin-EGFP was negligible or absent. The supporting cells' response was characterized by a rapid increase in $\beta$-actin-EGFP fluorescence followed by a single exponential decay (Fig. 2C). We defined the response lifetime as the sum of the measured rise time plus the half-life of exponential decay (see Materials and Methods). Measurements were compiled from 36 stereocilia excision events (four independent experiments), and the average response lifetime was calculated to be $21 \pm 2 \mathrm{~min}$ (Fig. 2D). Lifetime measurements encompassed the entire period of supporting cell remodeling, and thus significantly overestimated the actual time required for stereocilia excision, which could occur within 3-6 min of the cable forming (Fig. 2 A). Supporting cells displayed remarkable synchrony during stereocilia excision, activating within $180 \mathrm{~s}$ of each other (Fig. $2 \mathrm{~A}$; supplemental Movie 1, available at www.jneurosci.org as supplemental material). This high degree of coordination may indicate rapid recruitment by neighboring supporting cells, or the presence of a local trigger signal released by the hair cell. Furthermore, although supporting cells typically contacted several hair cells in the epithelium, their activity was targeted toward a single hair cell during the repair process (Fig. 2A). We conclude that supporting cells assemble an actin cable that can rapidly excise the hair cell stereocilia bundle while restoring the epithelial barrier.

\section{Supporting cells engulf the hair cell soma in a multicellular phagosome}

We next monitored the remaining hair cell soma to see whether it could survive within the epithelium without its apical pole (Gale et al., 2002; Jia et al., 2009). An additional 213 min elapsed before the hair cell soma was engulfed within a structure highlighted by $\beta$-actin-EGFP (Fig. 2 E; supplemental Movie 1, available at www. jneurosci.org as supplemental material). We subsequently show this structure to be phagocytic (see Fig. 3), and will refer to it as a supporting cell phagosome for clarity. The phagosome formed about the basolateral surfaces of the hair cell soma within 3-6 min, such that it completely encapsulated the hair cell soma (Fig. $2 E$, orthogonal). No significant difference was observed in recordings from mosaics in which both the hair cell and supporting cells expressed $\beta$-actin-EGFP, compared to those where only the supporting cells were labeled, and thus we concluded that the phagosome originated from supporting cells (supplemental Movie 2, available at www.jneurosci.org as supplemental material). Furthermore, in all the time-lapse sequences analyzed, we noted that the initial accumulation of $\beta$-actin-EGFP in the supporting cells was polarized to the cell surfaces contacting the targeted hair cell (Figs. 2E, 3A,B). This indicated that each supporting cell contributed to the multicellular phagosome. As the supporting cell phagosome matured, processes highlighted by $\beta$-actin-EGFP penetrated into the hair cell soma and physically disrupted it. By the end of this process, the hair cell soma was no longer evident within the epithelium. Similar to the process of stereocilia excision, cytoskeletal activity around the hair cell soma was highly synchronized with all supporting cells becoming activated within $180 \mathrm{~s}$ of each other. Phagocytosis was also spatially restricted to the targeted hair cell. Neighboring hair cells were spared, despite making contact with the exact same supporting cells. We conclude that in addition to removing the stereocilia bundle of a hair cell during aminoglycoside-induced trauma, supporting cells also act in concert to phagocytose the remaining hair cell soma from the epithelium (Fig. $2 H$ ).

Cytoskeletal kinetics during supporting cell phagocytosis were highly variable, and we could not use the same method of quantification as for stereocilia excision. Instead, we calculated the derivative of $\beta$-actin-EGFP fluorescence with respect to time (Fig. $2 F$ ) and measured how long this was significantly elevated above a baseline threshold (see Materials and Methods). We compiled lifetime measurements from 22 phagocytic events (four independent experiments) and found that the distribution was positively skewed around an average of $\sim 43 \pm 11 \mathrm{~min}$ (Fig. $2 G$ ). We noted that phagosome formation was simultaneous with, or more frequently lagged stereocilia excision with a delay of up to $5 \mathrm{~h}$ (Fig. $2 \mathrm{H}, \mathrm{I}$ ). In a limited number of records ( 4 of 21 events), we observed that phagocytosis could precede stereocilia excision by up to $50 \mathrm{~min}$. The variable timing of these two events suggested that both stereocilia excision and phagocytosis were independent mechanisms activated during aminoglycoside-induced ototoxicity. 
Formation of the supporting cell phagosome is closely correlated with loss of membrane integrity and hair cell death

Phagocytosis of apoptotic cells has been shown to promote cell death in Caenorhabditis elegans, a process referred to as engulfment-mediated cell death (Hoeppner et al., 2001; Reddien et al., 2001). We then investigated whether supporting cell activity, specifically stereocilia excision or phagocytosis, could occur in advance of hair cell death. To test this hypothesis, we performed five-dimensional imaging of $\beta$-actin-EGFP in combination with the nucleic acid binding dyes TOTO-3 (0.1 $\mu \mathrm{M})$ or PI $(1 \mu \mathrm{M})$ that were included in the bulk culture medium. TOTO-3 and PI are excluded by the intact plasma membrane of living cells and exhibit increased quantum yields as they bind to nucleic acids. Here we use this increased signal to report the loss of membrane integrity, an indicator of cell death. Streptomycin sulfate $(1 \mathrm{~mm})$ was used to induce hair cell death as before, and to minimize any phototoxicity caused by the additional laser excitation, the interval between $\mathrm{z}$-stack capture was increased to $5 \mathrm{~min}$. Two examples of TOTO-3/ $\beta$-actin-EGFP data sets are shown in Figure 3. In these examples only supporting cells were expressing $\beta$-actin-EGFP. At the beginning of the records, negligible TOTO-3 fluorescence was detected within either hair cells or supporting cells (Fig. 3A,B). Remarkably, no significant increase of TOTO-3 fluorescence was observed within the hair cell soma as the hair bundle was excised, indicating that the plasma membrane remained intact during this stage of the removal process (Fig. 3A; supplemental Movie 3, available at www.jneurosci.org as supplemental material). These data demonstrate that supporting cells can remove the stereocilia organelle and reform the epithelial junctions before a hair cell dies and becomes necrotic.

After stereocilia excision, we noted a strong correlation between the onset of supporting cell phagocytosis and the uptake of TOTO-3 into the hair cell soma. In the examples shown, phagosome formation initiated one frame in advance of (Fig. $3 A$ ) and in the same frame $(B)$ as TOTO-3 uptake. In both cases, TOTO-3 uptake was restricted to the targeted hair cell and was not observed within the neighboring supporting cells. Similar observations were made using PI as the membrane integrity marker (data not shown), and the data sets were combined for analysis. We quantified the delay (in frames) between the onset of phagosome formation $\left(F_{\text {phagocytosis }}\right)$ and dye uptake $\left(F_{\text {dye }}\right)$ as $F_{\text {delay }}=F_{\text {dye }}-F_{\text {phagocytosis }}$. A negative $F_{\text {delay }}$
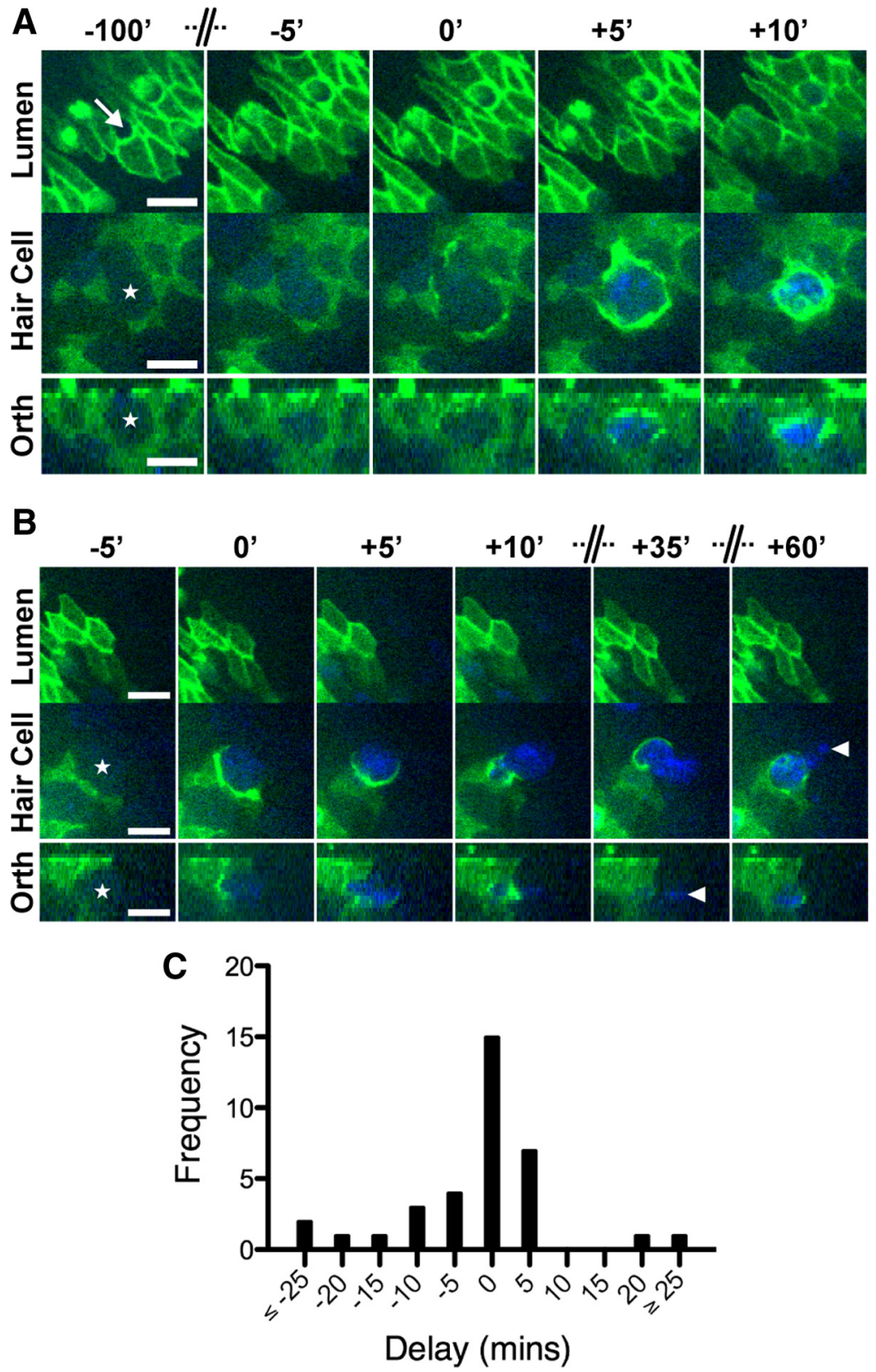

Figure 3. Supporting cells phagocytosis is closely correlated with hair cell death. Utricles (E17-E19) expressing $\beta$-actin-EGFP were incubated with $1 \mathrm{~mm}$ streptomycin and $0.1 \mu \mathrm{m}$ TOT0-3, a fluorescent nucleic acid dye excluded by the plasmalemma of viable cells. Dual-wavelength time-lapse images were captured for EGFP (green) and TOTO-3 (blue). $A, B$, Two examples where supporting cells expressing $\beta$-actin-EGFP remove nonexpressing hair cells (stars) from the sensory epithelium. The position of the hair cell bundle is marked in $\boldsymbol{A}$ (arrow). $\boldsymbol{A}$, Excision of the stereocilia bundle occurs with negligible uptake of TOTO-3 into the hair cell cytosol $\left(-100^{\prime}\right.$ to $\left.-5^{\prime}\right)$ (supplemental Movie 3, available at www.jneurosci.org as supplemental material). Significant uptake of TOT0-3 is observed as supporting cells engulf the hair cell soma within a phagosome $\left(+5^{\prime}\right)$. TOTO-3 fluorescence confirms that the phagosome contains chromatin and that the hair cell confined within is dead. $\boldsymbol{B}$, In the second example, uptake of TOTO-3 occurs with formation of the supporting cell phagosome. After the initial engulfment, ТОТО-3-labeled hair cell chromatin is transported into the supporting cells' cytoplasm. Not all of the hair cell nucleus is engulfed by the $\beta$-actin-EGFP-expressing supporting cell. Fragments of TОT0-3-labeled chromatin (arrowheads) remain either in the extracellular space or within supporting cells that did not express $\beta$-actin-EGFP. C, Histogram of time delays between the onset of supporting cell phagocytosis and TOTO-3/Pl uptake in hair cells ( $n=35$ events). The modal response was for these events to occur in the same frame, i.e., a delay of 0 min. Negative delays indicate that TOTO-3/PI uptake preceded phagosome formation and vice versa. Scale bars: $10 \mu \mathrm{m}$. Time is expressed in minutes, and the axis has been compressed where indicated.

delay indicated that dye uptake occurred before phagocytosis, whereas a positive $F_{\text {delay }}$ indicated that dye uptake occurred after phagocytosis. We analyzed the phagocytosis of 35 hair cells from three independent experiments and found the modal value of the $F_{\text {delay }}$ distribution to be zero (Fig. $3 C$ ). This indicated that the 

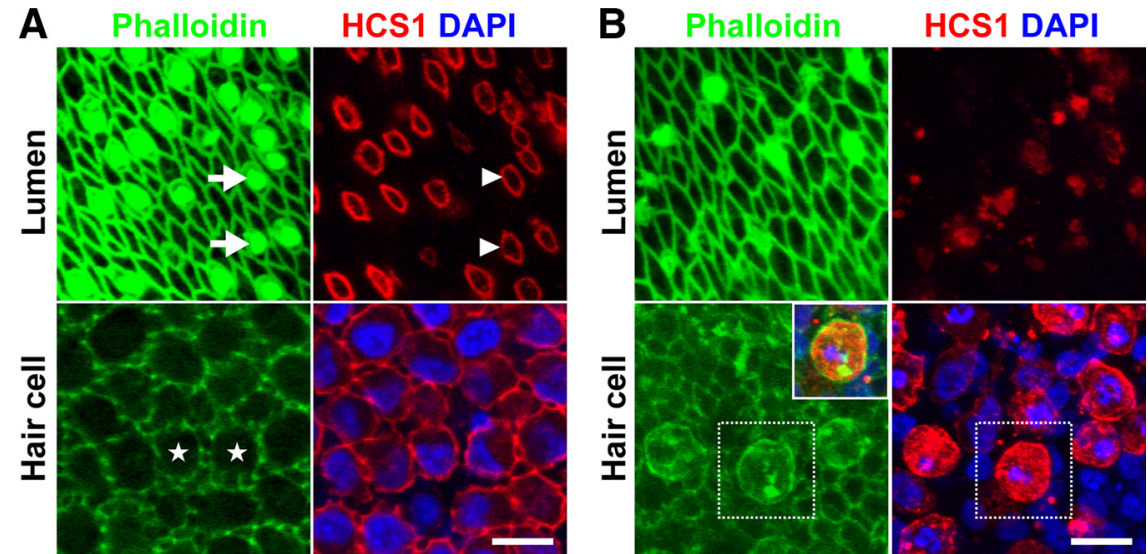

C

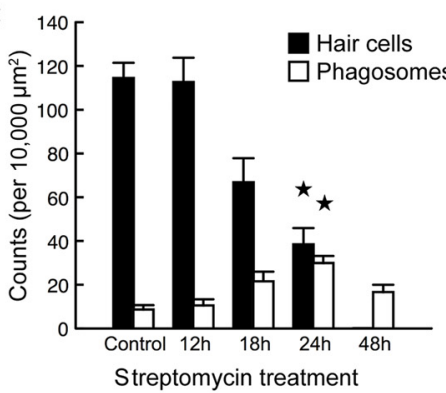

D
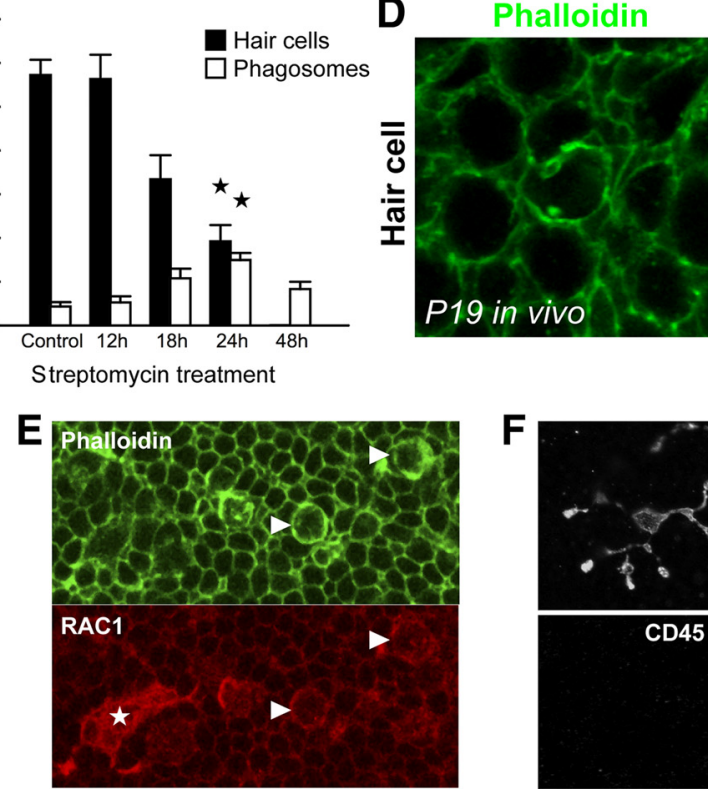

$\mathbf{F}$
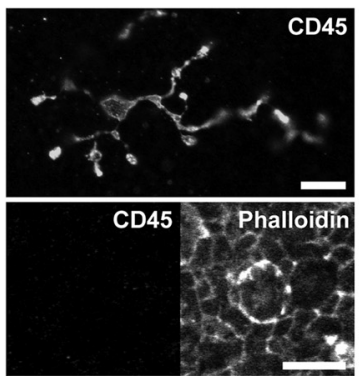

Figure 4. Supporting cell phagosomes are present in aminoglycoside-treated utricles, both in vitro and in vivo. Wild-type chick utricles (E21) were cultured with $1 \mathrm{~mm}$ streptomycin sulfate in vitro to induce hair cell toxicity. Paraformaldehyde fixed samples were labeled with anti-HCS-1, phalloidin, and DAPI, and then visualized using confocal microscopy. $\boldsymbol{A}$, Normal organization of the sensory epithelium after $24 \mathrm{~h}$ in vitro. Phalloidin highlights the stereocilia bundles at the epithelial lumen (arrows) and anti-HCS-1 labels the hair cell pericuticular junction (arrowheads). Within the epithelium, hair cell somas (stars) are packed densely together with HCS-1 labeling the basolateral membranes. $\boldsymbol{B}$, After 24 h exposure to $1 \mathrm{~mm}$ streptomycin, there is significant hair cell loss. Few stereocilia bundles are visible and this correlates with expansion of supporting cells at the epithelial lumen. At the luminal surface, the HCS-1-positive rings associated with the hair cell pericuticular regions are no longer visible. At the level of the hair cell nuclei, there are HCS-1-labeled cells containing pyknotic DNA. F-actin accumulates in phagosomes containing HCS-1 and pyknotic DNA (inset, overlay of boxed regions). C, Quantification of hair cell and phagosome density in utricles incubated with streptomycin for varying durations reveals an inverse relationship. A significant change is observed at $24 \mathrm{~h}$ (compared to sham-operated controls; $n=5$ utricles per group; ${ }^{\star} p<0.001$ ). D. Phagosomes were also detected in P19 utricles after systemic administration of streptomycin in vivo. E, F, Phagosomes colocalize with phagocytic, but not macrophages markers. Phagosomes (arrowheads) and a macrophage (star) both label with anti-RAC1 (CED-10) (E). However, phagosomes do not label with anti-CD45 (F, bottom), unlike macrophages $(\boldsymbol{F}$, top). Scale bars: $10 \mu \mathrm{m}$. Data are expressed as mean \pm SEM.

predominant response was for dye uptake to occur in the same frame as phagocytosis was initiated. In addition to monitoring hair cell integrity, TOTO-3 allowed us to track hair cell DNA and confirm that supporting cells were indeed phagocytic. After permeabilization of the hair cell soma, TOTO-3-labeled hair cell DNA was observed entering the cytoplasm of supporting cells. We observed the uptake of particles ranging from small puncta (data not shown) to entire nuclei (Fig. 3B). We conclude that the loss of hair cell membrane integrity occurred simultaneously with engulfment and phagocytosis by supporting cells. This removal mechanism likely prevents hair cells from undergoing sec-
HCS1 DAPI

ondary necrosis in situ and promotes the efficient removal of hair cell antigens from the epithelium.

Phagocytosis by supporting cells is a major mode of hair cell removal

We next investigated whether supporting cell phagocytic activity could be detected in wild-type tissues that were not infected with the $\operatorname{RCASBP}(\mathrm{B})-\beta$-actin-EGFP virus. Utricles from prehatch E21 chicks were cultured with $1 \mathrm{~mm}$ streptomycin sulfate for $24 \mathrm{~h}$ in vitro to induce hair cell death. A separate group of utricles were sham operated for an equivalent period of $24 \mathrm{~h}$ to serve as controls. After fixation, utricles were stained with phalloidin, DAPI and anti-HCS-1 to reveal hair cell somas (Gale et al., 2000; Goodyear et al., 2010). Utricles sham operated for $24 \mathrm{~h}$ in vitro retained excellent organotypic morphology with HCS-1-positive hair cells arranged in a regular fashion and stereocilia bundles projecting into the epithelial lumen (Fig. $4 A$ ). In contrast, utricles treated with streptomycin for $24 \mathrm{~h}$ had visible hair cell loss (Fig. 4B). Hair cell density was reduced from $114 \pm 7$ in controls, to $38 \pm$ 7 cells per $10,000 \mu \mathrm{m}^{2}$ (Fig. $\left.4 C\right)(p<$ $0.0001 ; n=5$ utricles per group). Our time-lapse studies predicted that as hair cell somas were lost from the epithelium, they would be engulfed by actin-based supporting cell phagosomes. Indeed, numerous structures bound by a cortex of F-actin were observed within the epithelium (Fig. 4B). Immunocytochemistry using HCS-1 and DAPI confirmed that these structures were both HCS-1 positive and contained pyknotic chromatin, and thus were the direct correlate of the supporting cell phagosomes described above using $\beta$-actin-EGFP (Fig. $4 B$, inset). We quantified the number of supporting cell phagosomes and found a significant 3.3-fold increase, from $9 \pm 2$ per $10,000 \mu \mathrm{m}^{2}$ in sham-operated controls to $30 \pm 3$ per $10,000 \mu \mathrm{m}^{2}$ in streptomycin-treated utricles $(p<0.001)$ (Fig. 4C). In an additional set of experiments, E21 utricles were incubated for 12, 18 , or $48 \mathrm{~h}$ in $1 \mathrm{~mm}$ streptomycin to establish the time course of phagosome appearance and hair cell loss. These experiments revealed an inverse correlation between phagosome and hair cell density as the duration of streptomycin treatment was increased (Fig. 4C), consistent with phagocytosis by supporting cells being a significant mode of hair cell removal.

Macrophages are recruited to sites of hair cell trauma, yet whether they play a role in phagocytosing hair cells is unclear (Warchol, 1997; Bhave et al., 1998; O'Halloran and Oesterle, 2004). To examine how macrophages might be integrated with supporting cell activity, we probed streptomycin-treated utricles with Av53, a monoclonal antibody that recognizes all isoforms of 

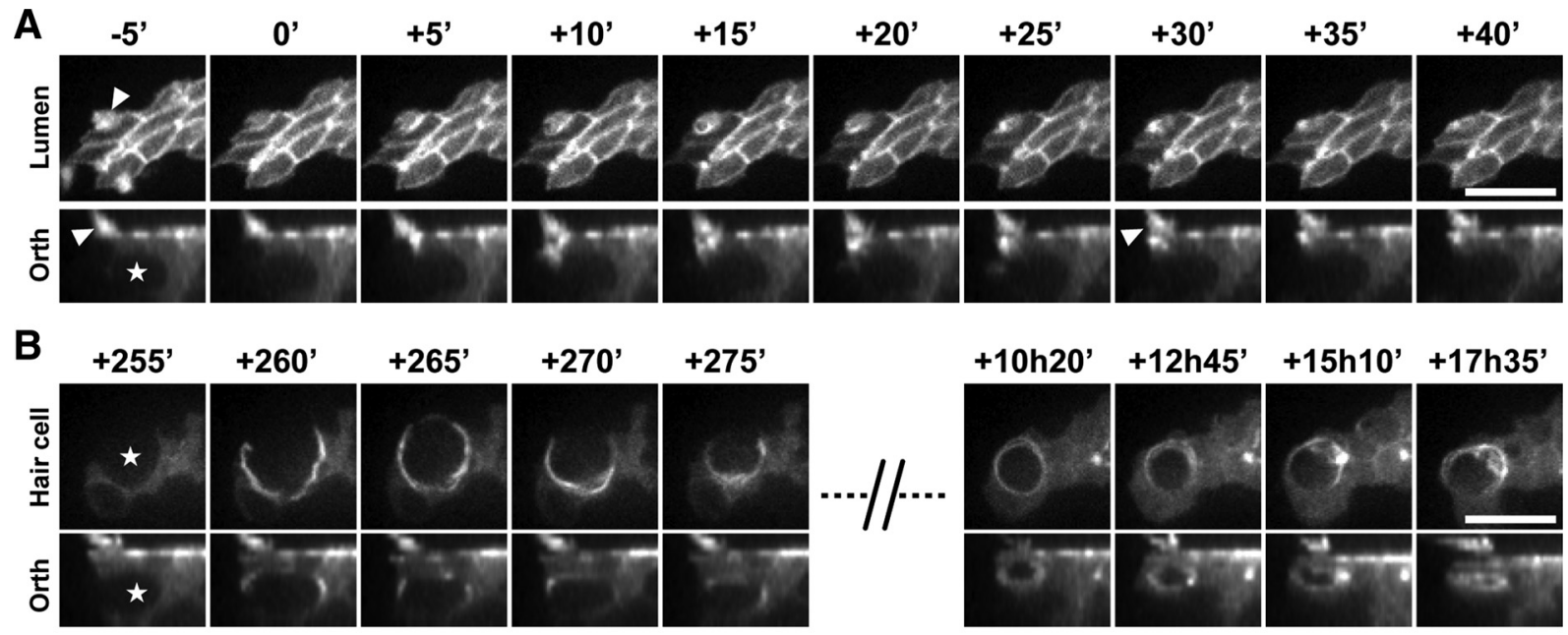

C

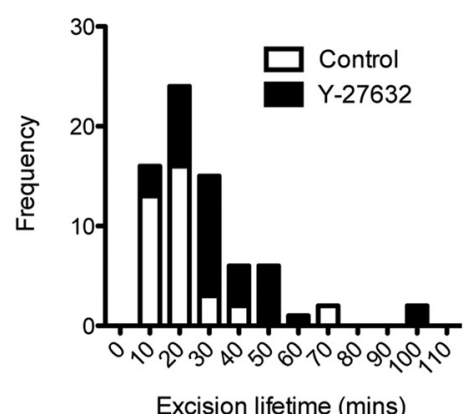

D

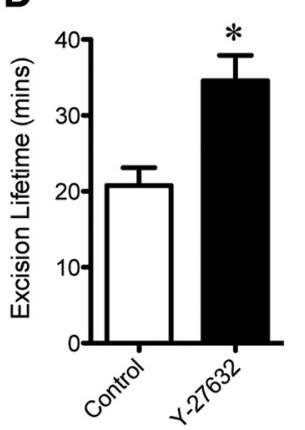

E

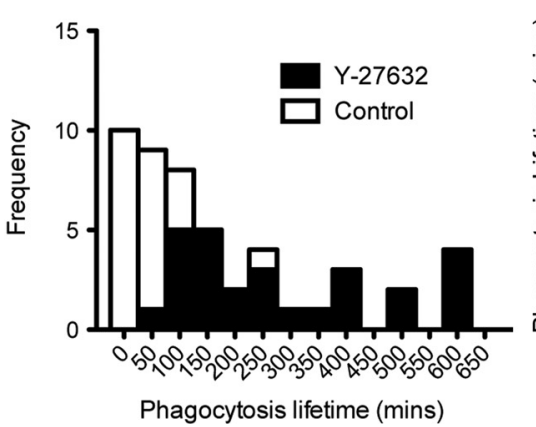

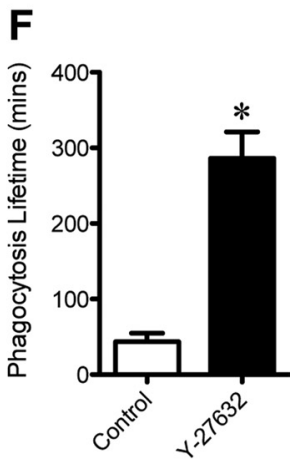

Figure 5. Rho kinase is required for efficient phagocytosis of hair cells during aminoglycoside treatment. Utricles expressing $\beta$-actin-EGFP were imaged in the continuous presence of $1 \mathrm{~mm}$ streptomycin and $30 \mu \mathrm{M} Y-27632$, a Rho-kinase inhibitor. $A, B$, Identical hair cell at different times during the repair process. Supporting cells and the hair cell (star) are both expressing $\beta$-actin-EGFP in this example. The hair cell stereocilia bundle is clearly visible $\left(-5^{\prime}\right.$; arrowhead). $A$, Inhibition of Rho kinase did not prevent stereocilia excision or repair of the epithelial junctions. After excision, the stereocilia bundle remains lying on the surface of the epithelium $\left(+30^{\prime}\right.$; arrowhead). № $\beta$-actin-EGFP activity was observed about the hair cell soma during this process. $\boldsymbol{B}$, Rho-kinase treatment did not block formation of the supporting phagosome $\left(+260^{\prime}\right)$, but did interfere with the uptake of the hair cell remains (star). The supporting cell phagosome persisted within the epithelium for extended periods, suggesting that Rho kinase was required for ingestion of the hair cell corpse. $C, D$, Quantification revealed that although Y-27632 did not prevent stereocilia excision, it significantly extended the duration of supporting cell activity $\left(n=36\right.$ events) when compared to controls in Figure 2 ( ${ }^{*} p<0.001$; Student's $t$ test). $\boldsymbol{E}$, $\boldsymbol{F}$, Treatment with Y-27632 significantly extended the duration of supporting cells' activity $\left(n=27\right.$ events) during phagocytosis compared with controls from Figure $2\left({ }^{*} p<0.001 ;\right.$ Mann-Whitney $U$ test). Data are expressed as mean \pm SEM. Scale bars: $10 \mu \mathrm{m}$. Time is expressed in minutes.

chicken CD45 (Dr. F Davison, personal communication). CD45 is a protein tyrosine phosphatase expressed by all cells of hematopoietic origin, except erythrocytes and platelets (Charbonneau et al., 1988). Immunocytochemistry for Av53 revealed highly ramified cell types characteristic of macrophages within the sensory epithelium (Fig. 4F). We quantified the number of Av53-positive cells within the epithelium after $24 \mathrm{~h}$ exposure to streptomycin to be $0.9 \pm 0.3$ cells per $10,000 \mu \mathrm{m}^{2}$ ( $n=3$ utricles). Critically, supporting cell phagosomes did not label with Av53, confirming that they were not associated with leukocytes, macrophages, or microglia. However, supporting cells phagosomes did colocalize with antisera recognizing $\mathrm{RACl}$ as they engulfed hair cells. RAC1 is a member of the Rho family of GTPases that orchestrate cytoskeletal remodeling (Jaffe and Hall, 2005) and is an ortholog of CED-10, a key effector protein in the cell corpse engulfment pathway of $C$. elegans (Reddien and Horvitz, 2000). RAC1 was localized to the basolateral membranes of all supporting cells, but was particularly concentrated in supporting cell phagosomes (Fig. 4E). RACl immunocytochemistry also revealed macrophages within the sensory epithelium (Fig. 4E). These data show that supporting cells express and likely share molecular components of corpse engulfment pathways used by other phagocytic cells.
Finally, we investigated the ability of supporting cells to phagocytose dying hair cells in vivo. Utricles were dissected from P21 chickens after daily systemic administration of streptomycin from P14 through P19 (see Materials and Methods). Although extrastriolar type II hair cells were significantly more resilient to aminoglycoside exposure in vivo, supporting cell phagosomes were still detected within the utricular sensory epithelium (Fig. $4 D$ ). We conclude that supporting cell phagocytosis is a general mechanism of hair cell removal in the avian vestibular system, both in vitro and in vivo.

Rho kinase is required for efficient hair cell phagocytosis To investigate the mechanisms by which supporting cells remove damaged hair cells, we studied the function of Rho kinase during streptomycin treatment. Rho-kinase activity is required for the formation of actin cables in UV-exposed MDCK epithelia (Rosenblatt et al., 2001). We hypothesized that inhibition of Rho kinase would similarly prevent formation of an actin cable, and thus inhibit excision of hair cell stereocilia during streptomycin toxicity. To test this, utricles expressing $\beta$-actin-EGFP were timelapse imaged live in the presence of both $1 \mathrm{~mm}$ streptomycin and $30 \mu \mathrm{M}$ Y-27632, a cell-permeant Rho-kinase inhibitor (Uehata et 
al., 1997). Inhibition of Rho kinase did not prevent either stereocilia excision or epithelial repair (Fig. $5 A$ ). We measured the average lifetime of the $\beta$-actin-EGFP signal observed during this process to be $35 \pm 3 \mathrm{~min}$ (Fig. $5 C)(n=36$ events, 4 independent experiments). Since the Y-27632 compound was reconstituted as a highly concentrated stock in water, we used our previous data set from Figure 2 as the appropriate vehicle control. Y-27632 elicited a significant 1.7-fold increase over control lifetimes of $21 \pm 2 \min (n=36 ; p=0.001)$ (Fig. $5 D)$. In a small number of examples, supporting cell lamellipodia erupted into the epithelial lumen as the hair bundle was excised (data not shown). These responses did not fit an exponential decay and were not included in this analysis. Despite a difference in kinetics, we conclude that the excision of hair cell stereocilia by supporting cells could still proceed in the absence of Rho-kinase activity.

Rho kinase is also required for certain types of receptormediated phagocytosis (Olazabal et al., 2002). We next hypothesized that inhibition of Rho kinase might similarly prevent the phagocytosis of dying hair cells by supporting cells. In the presence of $30 \mu \mathrm{M}$ Y-27632 we found that supporting cell phagosomes could still initially form around the hair cell (Fig. 5B). Once formed, however, phagosomes were observed to persist in the epithelium far longer than in control recordings. We measured the lifetime of $\beta$-actin-EGFP activity during supporting cell phagocytosis and found that the distribution of lifetimes was now much broader, with some extending up to $10 \mathrm{~h}$ (Fig. 5E). Accordingly, the average lifetime was increased significantly from $43 \pm$ $11(n=22$; control data from Fig. 2$)$ to $286 \pm 35 \mathrm{~min}(n=27 ; p<$ 0.0001; two-tailed Mann-Whitney $U$ test) (Fig. $5 F$ ). These data indicated that supporting cell phagosomes containing hair cell corpses should accumulate within the sensory epithelium while Rho kinase was inhibited. To independently verify this, we incubated E21 wild-type utricles for $24 \mathrm{~h}$ in vitro with $1 \mathrm{~mm}$ streptomycin combined with $30 \mu \mathrm{M} \mathrm{Y-27632} \mathrm{(Fig.} \mathrm{6).} \mathrm{Utricles} \mathrm{treated}$ with Y-27632 (Fig. 6B) had a clear excess of supporting cell phagosomes within the epithelium compared to vehicle controls treated with streptomycin alone (Fig. 6A). Supporting cell phagosomes still contained pyknotic hair cell chromatin as assessed by DAPI staining, indicating that Y-27632 did not offer significant protection against streptomycin toxicity (data not shown). Phagosome density was significantly increased from $30 \pm 3$ per $10,000 \mu \mathrm{m}^{2}(n=5)$ (Fig. 2) to $58 \pm 2(n=4$ utricles) in Y-27632-treated specimens $(p<0.001)$ (Fig. 6C). Combined with our time-lapse observations, the increase in phagosome density confirmed that Rho kinase was required for the efficient removal of hair cell corpses by supporting cells. Thus, in addition to repairing the epithelial lumen, supporting cells further maintain integrity by preventing the accumulation of dead hair cells during trauma.

\section{Discussion}

Epithelial homeostasis is vital for sensory transduction and hair cell survival in the inner ear. Our time-lapse recordings are the first to visualize the actin cytoskeleton in live organ explants, and they show that the sensory epithelium is highly dynamic during hair cell trauma. We find that supporting cells maintain epithelial homeostasis using two independent mechanisms to remove the hair bundle and eliminate the dying hair cell. Although our time-lapse experiments were performed in vitro using tissues explanted from late-stage prehatch embryos, we do not consider our findings to be developmental phenomena. The chicken inner ear matures rapidly and is already functional by the stages used in this study (Saunders et al., 1973; Jones and

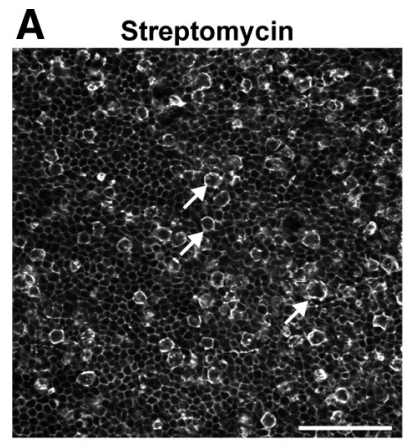

B Streptomycin + Y27632

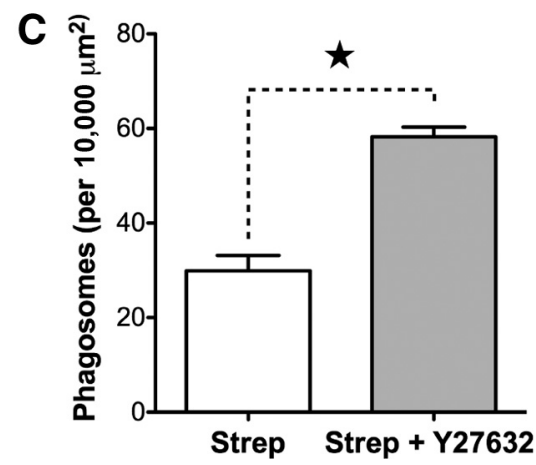

Figure 6. Inhibition of Rho kinase leads to accumulation of supporting cell phagosomes during aminoglycoside treatment. Wild-type chick utricles (E21) were incubated for $24 \mathrm{~h}$ in vitro with $1 \mathrm{~mm}$ streptomycin and $30 \mu \mathrm{m}$ Y-27632. $\boldsymbol{A}$, Phalloidin labeling reveals supporting cell phagosomes (arrows) within the epithelium of utricles treated with streptomycin alone. $\boldsymbol{B}$, Simultaneous treatment with streptomycin and $30 \mu \mathrm{m} Y-27632$ increases the density of phagosomes within the epithelium. C, Y-27632 treatment significantly increases the number of supporting cell phagosomes observed ( ${ }^{\star} p<0.001$ ). Data from Figure 4 were used as controls for statistical tests in C. Data are expressed as mean \pm SEM. Scale bars: $50 \mu \mathrm{m}$.

Jones, 2000). Moreover, we provide data using fixed tissues from postnatal animals that confirm the existence of supporting cell phagosomes in vivo.

A remarkable observation was the speed of stereocilia excision. Neighboring supporting cells assembled an actin cable about the circumference of the hair cell's pericuticular junction and constricted to excise the stereocilia bundle and cuticular plate while reforming the epithelial junctions. These data are the first direct demonstration of an actin cable involved in hair cell removal. Using different expression mosaics of $\beta$-actin-EGFP, we show that the cable originated in supporting cells immediately neighboring the hair cell. Supporting cell microfilaments have been identified invading beneath the cuticular plate of hair cell stereocilia in both amphibian and mammalian sensory epithelia (Forge, 1985; Li et al., 1995; Gale et al., 2002). Our time-lapse data are consistent with those observations and suggest that actin cable-mediated repair by supporting cells is common to all hair cell epithelia. Supporting cell actin cables may differ from those described in MDCK monolayers, where inhibition of Rho kinase blocks the extrusion of apoptotic cells and repair of the epithelium (Rosenblatt et al., 2001). Although removal of the apical pole and junction reformation was slowed in our experiments, it could still proceed in the presence of Y-27632, consistent with data from the bullfrog saccule (Hordichok and Steyger, 2007). We also noted that the supporting cell actin cables tended not to contract steadily around the hair cell, but invaded directly beneath the cuticular plate. This may reflect supporting cells moving along a path of least resistance, being unable to penetrate the dense cuticular plate. Alternatively, this may represent an adap- 
tation to improve the efficiency of repair in the inner ear, where neurotoxic endolymph likely exerts a strong selective pressure. In the majority of cases stereocilia excision occurred in advance of hair cell phagocytosis. Since phagocytosis was closely correlated with the uptake of DNA-binding dyes into hair cells, we infer that supporting cells were able to reseal the epithelial barrier before hair cell plasmalemmal integrity was compromised. This is supported by an ultrastructural study where electron-dense tracers were used to show that barrier integrity is maintained during aminoglycoside treatment (McDowell et al., 1989). Although our data clearly identify supporting cells as the major contributor to repair at the epithelial lumen, we cannot exclude involvement of the hair cell itself. Hirokawa and Tilney (1982) described a cable of bipolar actin filaments circumscribing the hair cell zonulae adherens, and proposed that it might modulate stereocilia mechanics. It is possible that this structure may have some role in the pulling together of supporting cell membranes during epithelial repair.

Our time-lapse recordings provide definitive evidence for the phagocytosis of hair cells by supporting cells and suggest that this is the primary mode of removal. Supporting cells engulfed the hair cell soma within an actin-based phagosome and internalized it over a period of $\sim 43 \mathrm{~min}$. This mechanism explains previous observations of pyknotic nuclei and hair cell antigens within the cytoplasm of mammalian supporting cells, again indicating a common removal mechanism (Li et al., 1995; Abrashkin et al., 2006). In the present experiments we did not find evidence that macrophages participated in the phagocytic activity we observed. However, we speculate that macrophages have an important secondary role scavenging hair cell remnants and antigens from the epithelium. In particular, macrophages may be required to phagocytose the excised stereocilia bundle from the luminal surface. The formation of the supporting cell phagosome was not prevented by treatment with Y-27632, indicating that Rho kinase was dispensable for the initial stages of hair cell removal. Instead, Y-27632 extended the lifetime of individual phagosomes, consistent with Rho kinase being required for internalization of hair cells by supporting cells, similar to complement receptormediated phagocytosis (Olazabal et al., 2002). As a result of delayed phagocytosis, we observed the accumulation of dead hair cells throughout the sensory epithelium. The impaired removal of dead cells is a primary event in the development of systemic autoimmunity (Nagata et al., 2010), and we speculate that a similar phenomenon may contribute to autoimmune inner ear disease, the etiology of which is currently unknown (Ruckenstein, 2004). Several genes linked to human deafness have been implicated in phagocytosis. The diaphanous-related formin mDial (DIAPH1) is required for phagocytosis in vitro (Colucci-Guyon et al., 2005), and a mutation in this gene associates with autosomal dominant deafness DFNA1 (Lynch et al., 1997). More intriguing are pathogenic mutations in $M Y H 9$ that segregate with human deafness in DFNA17 (Lalwani et al., 2000) and Fechtner syndrome (Seri et al., 2000). MYH9 is not only required for phagocytosis (Olazabal et al., 2002), but its activity is also targeted by Rho kinase (Kimura et al., 1996). It is now important to establish whether supporting cell activity described here in the chick is also present in the mammalian inner ear. Supporting cell activity may differ in the mammal, especially in the structurally complex organ of Corti where supporting cells are highly differentiated and provide an essential contribution to the overall mechanical properties of the system.

Formation of the supporting cell phagosome was correlated with uptake of DNA binding dyes into the hair cell's nucleus. We also noted from immunocytochemistry that supporting cell phagosomes always contained pyknotic hair cell chromatin. These observations indicate that the loss of membrane integrity signified the moment of hair cell death, a point of "no return" (Galluzzi et al., 2009). The most common response was for phagocytosis and dye uptake to occur in the same frame, although within our recording resolution of $5 \mathrm{~min}$ we cannot be certain whether both events were truly simultaneous or not. Higher-temporal-resolution recordings are now required to address this question. If phagosome formation lagged dye uptake, an interpretation might be that supporting cells were responding to the loss of hair cell integrity. Conversely, if phagosome formation preceded dye uptake, supporting cells could be implicated in precipitating the loss of hair cell integrity. The latter hypothesis echoes engulfment-mediated corpse removal, a developmental mechanism first reported in C. elegans where apoptotic cells are ingested by their neighbors (Reddien and Horvitz, 2004). Inhibition of the engulfment process allows apoptotic cells to escape death and ultimately survive, showing that even caspase- 3 activation can be a reversible state (Reddien et al., 2001). In support of a similar mechanism operating in the inner ear, we detected RAC1 GTPase, an ortholog of CED-10 (Reddien and Horvitz, 2000), accumulating in supporting cell membranes as they engulfed the hair cell. Might it be possible for apoptotic hair cells to be rescued by inhibiting supporting cell phagocytosis? A convincing test of this idea would be to inhibit supporting cell phagosome formation and assay whether hair cell loss is reduced or not. Recent reports of a conditional Racl allele should allow this hypothesis to be tested in the mouse (Grimsley-Myers et al., 2009).

Our data demonstrate that supporting cells can eliminate a sensory hair cell within minutes and that this process is precisely orchestrated. If supporting cell intervention was slow or impaired in any way, this might allow hair cells to undergo necrosis in situ. Moreover, inappropriate activation of this process could trigger removal of traumatized, yet ultimately viable hair cells, or perhaps even undamaged hair cells. Understanding how supporting cells sense hair cell trauma and engage the removal process is thus of great interest. Supporting cell activation was highly coordinated and polarized toward a targeted hair cell. These observations imply that supporting cells responded to high-fidelity, spatially restricted signals originating from the damaged hair cell. One such "eat me" signal may be the release of ATP from the damaged hair cell. Release of ATP by damaged neurons can recruit microglia (Davalos et al., 2005) and promote phagocytic clearance in the CNS (Elliott et al., 2009). Similarly, elevated levels of ATP have been reported in the endolymph of noisedamaged cochlea (Munoz et al., 2001), and exogenous ATP is known to stimulate calcium and MAP kinase signaling in supporting cells (Gale et al., 2004; Lahne and Gale, 2008; Mann et al., 2009). Another candidate hair cell removal signal is externalization of phosphatidylserine (PS) to the outer leaflet of the plasma membrane (Ravichandran and Lorenz, 2007). Rapid externalization of PS has been reported at the hair cell's apical pole in response to aminoglycoside exposure, though whether or when PS exposure occurs at the basolateral membrane after longer term aminoglycoside treatment is unclear (Shi et al., 2007; Goodyear et al., 2008). Supporting cells might also sense the production of radical oxygen species by traumatized hair cells (Hirose et al., 1997), a cue used by macrophages in wounded zebrafish and Drosophila larvae (Niethammer et al., 2009; Moreira et al., 2010). Future work needs to examine whether any one or a combination of these signals is required for hair cell removal. In conclusion, 
our data reveal that supporting cells have an active role during hair cell death. Current therapeutic approaches to preventing sensory loss focus on hair cells alone. It remains to be seen whether targeting supporting cells, in addition to hair cells, might be an effective approach to protecting and extending the life of damaged hair cells in vivo.

\section{References}

Abrashkin KA, Izumikawa M, Miyazawa T, Wang CH, Crumling MA, Swiderski DL, Beyer LA, Gong TW, Raphael Y (2006) The fate of outer hair cells after acoustic or ototoxic insults. Hear Res 218:20-29.

Bement WM, Forscher P, Mooseker MS (1993) A novel cytoskeletal structure involved in purse string wound closure and cell polarity maintenance. J Cell Biol 121:565-578.

Ben-Yosef T, Belyantseva IA, Saunders TL, Hughes ED, Kawamoto K, Van Itallie CM, Beyer LA, Halsey K, Gardner DJ, Wilcox ER, Rasmussen J, Anderson JM, Dolan DF, Forge A, Raphael Y, Camper SA, Friedman TB (2003) Claudin 14 knockout mice, a model for autosomal recessive deafness DFNB29, are deaf due to cochlear hair cell degeneration. Hum Mol Genet 12:2049-2061.

Bhave SA, Oesterle EC, Coltrera MD (1998) Macrophage and microglia-like cells in the avian inner ear. J Comp Neurol 398:241-256.

Bohne BA, Rabbitt KD (1983) Holes in the reticular lamina after noise exposure: implication for continuing damage in the organ of Corti. Hear Res 11:41-53.

Charbonneau H, Tonks NK, Walsh KA, Fischer EH (1988) The leukocyte common antigen (CD45): a putative receptor-linked protein tyrosine phosphatase. Proc Natl Acad Sci U S A 85:7182-7186.

Colucci-Guyon E, Niedergang F, Wallar BJ, Peng J, Alberts AS, Chavrier P (2005) A role for mammalian diaphanous-related formins in complement receptor (CR3)-mediated phagocytosis in macrophages. Curr Biol 15:2007-2012.

Daudet N, Lewis J (2005) Two contrasting roles for Notch activity in chick inner ear development: specification of prosensory patches and lateral inhibition of hair-cell differentiation. Development 132:541-551.

Davalos D, Grutzendler J, Yang G, Kim JV, Zuo Y, Jung S, Littman DR, Dustin ML, Gan WB (2005) ATP mediates rapid microglial response to local brain injury in vivo. Nat Neurosci 8:752-758.

Elliott MR, Chekeni FB, Trampont PC, Lazarowski ER, Kadl A, Walk SF, Park D, Woodson RI, Ostankovich M, Sharma P, Lysiak JJ, Harden TK, Leitinger N, Ravichandran KS (2009) Nucleotides released by apoptotic cells act as a find-me signal to promote phagocytic clearance. Nature 461:282-286.

Forge A (1985) Outer hair cell loss and supporting cell expansion following chronic gentamicin treatment. Hear Res 19:171-182.

Forge A, Li L (2000) Apoptotic death of hair cells in mammalian vestibular sensory epithelia. Hear Res 139:97-115.

Furness DN, Katori Y, Mahendrasingam S, Hackney CM (2005) Differential distribution of beta- and gamma-actin in guinea-pig cochlear sensory and supporting cells. Hear Res 207:22-34.

Gale JE, Meyers JR, Corwin JT (2000) Solitary hair cells are distributed throughout the extramacular epithelium in the bullfrog's saccule. J Assoc Res Otolaryngol 1:172-182.

Gale JE, Marcotti W, Kennedy HJ, Kros CJ, Richardson GP (2001) FM1-43 dye behaves as a permeant blocker of the hair-cell mechanotransducer channel. J Neurosci 21:7013-7025.

Gale JE, Meyers JR, Periasamy A, Corwin JT (2002) Survival of bundleless hair cells and subsequent bundle replacement in the bullfrog's saccule. J Neurobiol 50:81-92.

Gale JE, Piazza V, Ciubotaru CD, Mammano F (2004) A mechanism for sensing noise damage in the inner ear. Curr Biol 14:526-529.

Galluzzi L, Aaronson SA, Abrams J, Alnemri ES, Andrews DW, Baehrecke EH, Bazan NG, Blagosklonny MV, Blomgren K, Borner C, Bredesen DE, Brenner C, Castedo M, Cidlowski JA, Ciechanover A, Cohen GM, De Laurenzi V, De Maria R, Deshmukh M, Dynlacht BD, et al. (2009) Guidelines for the use and interpretation of assays for monitoring cell death in higher eukaryotes. Cell Death Differ 16:1093-1107.

Goodyear RJ, Gale JE, Ranatunga KM, Kros CJ, Richardson GP (2008) Aminoglycoside-induced phosphatidylserine externalization in sensory hair cells is regionally restricted, rapid, and reversible. J Neurosci 28:9939-9952.

Goodyear RJ, Legan KP, Christiansen JR, Xia B, Korchagina J, Gale JE,
Warchol ME, Corwin JT, Richardson GP (2010) Identification of the hair-cell soma-1 antigen, HSC-1, as otoferlin. J Assoc Res Otolaryngol. Advance online publication. Retrieved September 2, 2010. doi: 10.1007/s10162-010-0231-6.

Grimsley-Myers CM, Sipe CW, Geleoc GS, Lu X (2009) The small GTPase Rac1 regulates auditory hair cell morphogenesis. J Neurosci 29: 15859-15869.

Hamburger V, Hamilton HL (1992) A series of normal stages in the development of the chick embryo. 1951. Dev Dyn 195:231-272.

Hawkins JE Jr (1973) Comparative otopathology: aging, noise, and ototoxic drugs. Adv Otorhinolaryngol 20:125-141.

Hirokawa N, Tilney LG (1982) Interactions between actin filaments and between actin filaments and membranes in quick-frozen and deeply etched hair cells of the chick ear. J Cell Biol 95:249-261.

Hirose K, Hockenbery DM, Rubel EW (1997) Reactive oxygen species in chick hair cells after gentamicin exposure in vitro. Hear Res 104:1-14.

Hoeppner DJ, Hengartner MO, Schnabel R (2001) Engulfment genes cooperate with ced-3 to promote cell death in Caenorhabditis elegans. Nature 412:202-206.

Hordichok AJ, Steyger PS (2007) Closure of supporting cell scar formations requires dynamic actin mechanisms. Hear Res 232:1-19.

Hudspeth AJ (1997) How hearing happens. Neuron 19:947-950.

Hughes SH, Greenhouse JJ, Petropoulos CJ, Sutrave P (1987) Adaptor plasmids simplify the insertion of foreign DNA into helper-independent retroviral vectors. J Virol 61:3004-3012.

Jaffe AB, Hall A (2005) Rho GTPases: biochemistry and biology. Annu Rev Cell Dev Biol 21:247-269.

Jia S, Yang S, Guo W, He DZ (2009) Fate of mammalian cochlear hair cells and stereocilia after loss of the stereocilia. J Neurosci 29:15277-15285.

Jones SM, Jones TA (2000) Ontogeny of vestibular compound action potentials in the domestic chicken. J Assoc Res Otolaryngol 1:232-242.

Kimura K, Ito M, Amano M, Chihara K, Fukata Y, Nakafuku M, Yamamori B, Feng J, Nakano T, Okawa K, Iwamatsu A, Kaibuchi K (1996) Regulation of myosin phosphatase by Rho and Rho-associated kinase (Rho-kinase). Science 273:245-248.

Lahne M, Gale JE (2008) Damage-induced activation of ERK1/2 in cochlear supporting cells is a hair cell death-promoting signal that depends on extracellular ATP and calcium. J Neurosci 28:4918-4928.

Lalwani AK, Goldstein JA, Kelley MJ, Luxford W, Castelein CM, Mhatre AN (2000) Human nonsyndromic hereditary deafness DFNA17 is due to a mutation in nonmuscle myosin MYH9. Am J Hum Genet 67:1121-1128.

Li L, Nevill G, Forge A (1995) Two modes of hair cell loss from the vestibular sensory epithelia of the guinea pig inner ear. J Comp Neurol 355:405-417.

Lynch ED, Lee MK, Morrow JE, Welcsh PL, Leon PE, King MC (1997) Nonsyndromic deafness DFNA1 associated with mutation of a human homolog of the Drosophila gene diaphanous. Science 278:1315-1318.

Mann ZF, Duchen MR, Gale JE (2009) Mitochondria modulate the spatiotemporal properties of intra- and intercellular $\mathrm{Ca} 2+$ signals in cochlear supporting cells. Cell Calcium 46:136-146.

Marcotti W, van Netten SM, Kros CJ (2005) The aminoglycoside antibiotic dihydrostreptomycin rapidly enters mouse outer hair cells through the mechano-electrical transducer channels. J Physiol 567:505-521.

Martin P, Lewis J (1992) Actin cables and epidermal movement in embryonic wound healing. Nature 360:179-183.

Matsui JI, Oesterle EC, Stone JS, Rubel EW (2000) Characterization of damage and regeneration in cultured avian utricles. J Assoc Res Otolaryngol $1: 46-63$.

Matsui JI, Haque A, Huss D, Messana EP, Alosi JA, Roberson DW, Cotanche DA, Dickman JD, Warchol ME (2003) Caspase inhibitors promote vestibular hair cell survival and function after aminoglycoside treatment in vivo. J Neurosci 23:6111-6122.

McDowell B, Davies S, Forge A (1989) The effect of gentamicin-induced hair cell loss on the tight junctions of the reticular lamina. Hear Res 40:221-232.

Meyers JR, Corwin JT (2007) Shape change controls supporting cell proliferation in lesioned mammalian balance epithelium. J Neurosci 27:4313-4325.

Moreira S, Stramer B, Evans I, Wood W, Martin P (2010) Prioritization of competing damage and developmental signals by migrating macrophages in the Drosophila embryo. Curr Biol 20:464-470.

Morgan BA, Fekete DM (1996) Manipulating gene expression with replicationcompetent retroviruses. Methods Cell Biol 51:185-218. 
Munoz DJ, Kendrick IS, Rassam M, Thorne PR (2001) Vesicular storage of adenosine triphosphate in the guinea-pig cochlear lateral wall and concentrations of ATP in the endolymph during sound exposure and hypoxia. Acta Otolaryngol 121:10-15.

Nagata S, Hanayama R, Kawane K (2010) Autoimmunity and the clearance of dead cells. Cell 140:619-630.

Nakano Y, Kim SH, Kim HM, Sanneman JD, Zhang Y, Smith RJ, Marcus DC, Wangemann P, Nessler RA, Banfi B (2009) A claudin-9-based ion permeability barrier is essential for hearing. PLoS Genet 5:e1000610.

Niethammer P, Grabher C, Look AT, Mitchison TJ (2009) A tissue-scale gradient of hydrogen peroxide mediates rapid wound detection in zebrafish. Nature 459:996-999.

O'Halloran EK, Oesterle EC (2004) Characterization of leukocyte subtypes in chicken inner ear sensory epithelia. J Comp Neurol 475:340-360.

Olazabal IM, Caron E, May RC, Schilling K, Knecht DA, Machesky LM (2002) Rho-kinase and myosin-II control phagocytic cup formation during CR, but not FcgammaR, phagocytosis. Curr Biol 12:1413-1418.

Pirvola U, Xing-Qun L, Virkkala J, Saarma M, Murakata C, Camoratto AM, Walton KM, Ylikoski J (2000) Rescue of hearing, auditory hair cells, and neurons by CEP-1347/KT7515, an inhibitor of c-Jun N-terminal kinase activation. J Neurosci 20:43-50.

Raphael Y, Altschuler RA (1991) Reorganization of cytoskeletal and junctional proteins during cochlear hair cell degeneration. Cell Motil Cytoskeleton 18:215-227.

Ravichandran KS, Lorenz U (2007) Engulfment of apoptotic cells: signals for a good meal. Nat Rev Immunol 7:964-974.

Reddien PW, Horvitz HR (2000) CED-2/CrkII and CED-10/Rac control phagocytosis and cell migration in Caenorhabditis elegans. Nat Cell Biol 2:131-136.

Reddien PW, Horvitz HR (2004) The engulfment process of programmed cell death in Caenorhabditis elegans. Annu Rev Cell Dev Biol 20:193-221.

Reddien PW, Cameron S, Horvitz HR (2001) Phagocytosis promotes programmed cell death in C. elegans. Nature 412:198-202.

Riazuddin S, Ahmed ZM, Fanning AS, Lagziel A, Kitajiri S, Ramzan K, Khan SN, Chattaraj P, Friedman PL, Anderson JM, Belyantseva IA, Forge A, Friedman TB (2006) Tricellulin is a tight-junction protein necessary for hearing. Am J Hum Genet 79:1040-1051.

Rosenblatt J, Raff MC, Cramer LP (2001) An epithelial cell destined for apoptosis signals its neighbors to extrude it by an actin- and myosindependent mechanism. Curr Biol 11:1847-1857.

Ruckenstein MJ (2004) Autoimmune inner ear disease. Curr Opin Otolaryngol Head Neck Surg 12:426-430.
Rzadzinska AK, Schneider ME, Davies C, Riordan GP, Kachar B (2004) An actin molecular treadmill and myosins maintain stereocilia functional architecture and self-renewal. J Cell Biol 164:887-897.

Saunders JC, Coles RB, Gates GR (1973) The development of auditory evoked responses in the cochlea and cochlear nuclei of the chick. Brain Res 63:59-74.

Schneider ME, Belyantseva IA, Azevedo RB, Kachar B (2002) Rapid renewal of auditory hair bundles. Nature 418:837-838.

Seri M, Cusano R, Gangarossa S, Caridi G, Bordo D, Lo Nigro C, Ghiggeri GM, Ravazzolo R, Savino M, Del Vecchio M, d'Apolito M, Iolascon A, Zelante LL, Savoia A, Balduini CL, Noris P, Magrini U, Belletti S, Heath KE, Babcock M, et al. (2000) Mutations in MYH9 result in the MayHegglin anomaly, and Fechtner and Sebastian syndromes. The MayHeggllin/Fechtner Syndrome Consortium. Nat Genet 26:103-105.

Shi X, Gillespie PG, Nuttall AL (2007) Apical phosphatidylserine externalization in auditory hair cells. Mol Membr Biol 24:16-27.

Slattum G, McGee KM, Rosenblatt J (2009) P115 RhoGEF and microtubules decide the direction apoptotic cells extrude from an epithelium. J Cell Biol 186:693-702.

Uehata M, Ishizaki T, Satoh H, Ono T, Kawahara T, Morishita T, Tamakawa H, Yamagami K, Inui J, Maekawa M, Narumiya S (1997) Calcium sensitization of smooth muscle mediated by a Rho-associated protein kinase in hypertension. Nature 389:990-994.

Wang Y, Hirose K, Liberman MC (2002) Dynamics of noise-induced cellular injury and repair in the mouse cochlea. J Assoc Res Otolaryngol 3:248-268.

Wangemann P (2006) Supporting sensory transduction: cochlear fluid homeostasis and the endocochlear potential. J Physiol 576:11-21.

Warchol ME (1997) Macrophage activity in organ cultures of the avian cochlea: demonstration of a resident population and recruitment to sites of hair cell lesions. J Neurobiol 33:724-734.

Warchol ME, Speck JD (2007) Expression of GATA3 and tenascin in the avian vestibular maculae: normative patterns and changes during sensory regeneration. J Comp Neurol 500:646-657.

Wilcox ER, Burton QL, Naz S, Riazuddin S, Smith TN, Ploplis B, Belyantseva I, Ben-Yosef T, Liburd NA, Morell RJ, Kachar B, Wu DK, Griffith AJ, Friedman TB (2001) Mutations in the gene encoding tight junction claudin-14 cause autosomal recessive deafness DFNB29. Cell 104:165-172.

Wood W, Jacinto A, Grose R, Woolner S, Gale J, Wilson C, Martin P (2002) Wound healing recapitulates morphogenesis in Drosophila embryos. Nat Cell Biol 4:907-912. 